\title{
Family business research: Reviewing the past, contemplating the future
}

\author{
George Haynes ${ }^{1}$ (D) Maria Marshall ${ }^{2} \cdot$ Yoon Lee ${ }^{3} \cdot$ Virginia Zuiker $^{4} \cdot$ Cynthia R. Jasper $^{5} \cdot$ Sandra Sydnor $^{2}$. \\ Corinne Valdivia ${ }^{6} \cdot$ Diane Masuo $^{7} \cdot$ Linda Niehm $^{8} \cdot$ Renee Wiatt ${ }^{2}$
}

Accepted: 15 October 2020 / Published online: 31 October 2020

(c) Springer Science+Business Media, LLC, part of Springer Nature 2020

\begin{abstract}
This paper reviews articles published in the Journal of Family and Economic Issues (JFEI) from 2010 to 2019 and considers future research opportunities. The JFEI articles utilize theories and conceptual frameworks from several social science fields, to help readers understand the importance of including both the family and business in any discussion of family businesses. The literature review addresses four family business topical areas: (1) household and business economics, (2) business continuity and succession, (3) managerial and adoption strategies, and (4) values and goals. These JFEI articles have focused on differentiating family businesses from other types of businesses; explaining the unique interface between the family and the business; and identifying the characteristics (i.e., demographics, adjustment strategies, continuity, capitals, and values and goals) for family business survival and success. In the future, family business researchers have the opportunity to better understand the impact of community resources and climate; more carefully assess the challenges of women, minorities, and immigrants; understand the role of cultural capital; and explore the impact of innovation during rapidly changing times, such as those created by the pandemic.
\end{abstract}

Keywords Family business $\cdot$ Survival $\cdot$ Success $\cdot$ Succession $\cdot$ Adoption strategies $\cdot$ Value orientation $\cdot$ Goals

\section{Introduction}

This is one of several papers published together in Journal of Family and Economic Issues on the "Special Issue on Virtual Decade in Review".

George Haynes

haynes@montana.edu

Maria Marshall

mimarshal@purdue.edu

Yoon Lee

yoon.lee@usu.edu

Virginia Zuiker

vzuiker@umn.edu

Cynthia R. Jasper

crjasper@wisc.edu

Sandra Sydnor

ssydnorb@purdue.edu

Corinne Valdivia

ValdiviaC@missouri.edu

Diane Masuo

masuo@hawaii.edu
This literature review addresses two important questions about family business research: (1) what did we learn from the Journal of Family and Economic Issues (JFEI) articles

\author{
Linda Niehm \\ niehmlin@iastate.edu \\ Renee Wiatt \\ reneewiatt@purdue.edu \\ 1 Montana State University, Bozeman, MT, USA \\ 2 Purdue University, West Lafayette, IN, USA \\ 3 Utah State University, Logan, UT, USA \\ 4 University of Minnesota, Minneapolis, MN, USA \\ 5 University of Wisconsin, Madison, WI, USA \\ 6 University of Missouri, Columbia, MO, USA \\ 7 University of Hawaii, Honololo, HI, USA \\ 8 Iowa State University, Ames, IA, USA
}


published over the past decade; and (2) where do we go from here. The JFEI articles have helped readers better understand family businesses by differentiating them from other types of businesses; explaining the unique interface between the family and the business; and identifying the characteristics (i.e., demographics, adjustment strategies, continuity, capitals, and values and goals) for family business survival and success. This JFEI family business literature review was guided by an article by Yilmazer and Schrank (2010). The reviews of published JFEI family business articles were driven by the notion that an understanding of the family and the business is critical in the understanding of the sustainability of family businesses. Looking forward, family business researchers have the opportunity to better understand the impact of community resources and climate; more carefully assess the challenges of women, minorities, and immigrants; understand the role of cultural capital; and explore the impact of innovation during rapidly changing times, such as those created by the pandemic.

The guest editor assigned 20 articles on family business published between 2010 and 2019 for this review. The scholars generating this research were from universities, government agencies and businesses throughout the US. Ten of the twenty papers were authored by members of the North Central Region's Agricultural Experiment Station Project on family business. Those research faculty members were from land grant institutions throughout the central and western US. Nearly all of the authors were applied economists in agricultural economics, family or consumer economics, family business, or family resource management.

The 20 published JFEI articles helped readers identify the attributes of the family and the business that are important for family business survival and success. While a substantial body of the family business literature has been generated by business faculty, this literature goes beyond the traditional business approach by integrating researchers from social sciences, including: family and social scientists, sociologists, psychologists, family economists, and others into the discussion. The strength of the JFEI literature is the innovative ideas that have come from the research of scholars from several disciplines. For additional information on authors, disciplines, and affiliations see Appendix Table 1.

The JFEI family business articles made substantial contributions to research on family businesses by utilizing high-quality secondary data, innovative primary data, and established theoretical and conceptual frameworks. The family business articles published in JFEI used eight high quality secondary datasets. They were: 1) American Family Business Survey, 2) National Family Business Survey, 3)
Spatial Hazards and Losses Data for the US, 4) Survey of Consumer Finances, 5) National Minority Business Owners Survey, 6) Intergenerational Family Business Survey, and 7) Survey of Household Finances in Spain, and 8) Arthur Anderson Center for Family Business Survey. In addition, primary data on family businesses, including farms, were used in studies in the United States, United Kingdom, Norway, India, and Australia. Nationally representative samples were available to researchers using the American Family Business Survey, National Family Business Survey, Spatial Hazards and Losses Data for the US, Survey of Consumer Finances, National Minority Business Owners Survey and Survey of Household Finances in Spain.

Of the 20 articles reviewed in this paper, 15 were based on quantitative research followed by three on qualitative research, and two were literature reviews. Fourteen established theoretical and conceptual models used by the authors, include the following: 1) Sustainable Family Business Theory (Stafford et al. 1999), 2) Agricultural Household Model (Singh et al. 1986), 3) General Systems Theory (von Bertalanffy 1976), 4) Technology Acceptance Model (Davis et al. 1989), 5) Diffusion of Innovations Framework (Rogers 2003), 6) Strategic Management Framework (Sharma et al. 1997), 7) Social Exchange Theory (Emerson 1981), 8) Financial Satisfaction Framework (Joo and Grable 2004), 9) Farming Satisfaction Model (Coughenour and Swanson 1992), 10) Role Theory (Biddle 1986), 11) Fundamental Interpersonal Relations Orientations (Schutz 1958), 12) Dynamic Capabilities Approach (Teece et al. 1997), 13) Unified Systems Model (Habbershon et al. 2003), and 14) Family Resource Management (Deacon and Firebaugh 1988). These papers have addressed several important concepts, including disruptions, survival and success, and adoption strategies. For instance, the concept of disruption covers changes in farm programs to substantial weather events, such as Hurricane Katrina; success covers objective measures, such as changes in profits to subjective measures, such as asking the respondent if they believed they were successful. Adoption strategies consider responses to changes by family business owners, such as hiring additional help, an adjustment strategy, to adopting new technologies. While selected articles refer to households and others refer to families, these terms are synonymous in these studies. They refer to businesses owned or managed by family members related by birth, marriage, or adoption. For additional information on methods, theories, concepts, and frameworks see Appendix Table 2. 
The JFEI family business articles summarize issues representing four topical areas: (1) household and business economics, (2) business continuity and succession, (3) managerial and adoption strategies, and (4) values and goals. The household and business economics topic covers cash flow problems, profit growth, perceived business success, savings behavior, survival duration, and ownership profitability, satisfaction, and perceived well-being. Business continuity and succession topics include continuation commitment, daughter succession, and entrepreneurial skill succession. Topics in the managerial and adoption strategy category include adjustment strategies, capital usage, and innovative technology adoption. The values and goals section addresses value orientation, goal orientation and performance, dynamic capabilities, and considerate exchange.

\section{Household and business economics}

The household and business economics literature recognized the importance of conducting holistic analyses when considering family business. A literature review by Yilmazer and Schrank (2010) provided an important foundation for examining resource flows between the family and business. This article carefully distinguished between bootstrapping from the small business finance literature and intermingling from the household and family firm literature in small and family-owned businesses. The authors concluded that both bodies of literature, taken individually, were not sufficiently comprehensive to fully capture the financial flows between the household and business and the factors that affect their utilization. The authors suggested that these two groups of research studies intersect and their merger would enable business and household finances to be more holistically understood for family businesses.

\section{Family business response to cash flow problems}

The foundation provided by Yilmazer and Schrank (2010) was important in the development of a research study by McDonald and Marshall (2018), which used Sustainable Family Business Theory (SFBT) and Intergeneration Family Business Survey data. McDonald and Marshall examined family business resource transfers and tensions to determine how the household and the business respond to cash flow problems. The authors found that cash flow problems increased resource tension in both the household and the business. When faced with family cash flow problems, the business did not transfer more funds to the household either because the business owner was unable or unwilling to transfer more funds to the household. When faced with business cash flow problems, family businesses responded by allocating less cash to the household. These results suggest that family businesses held on to financial resources to help the business, rather than the household.

\section{Profit growth and perceived business success}

Positive business or household cash flow depends on the generation of business profits or other financial resources. A study by Lee et al. (2010), using the SFBT and National Family Business Survey, examined gender differences in profit growth. Most importantly, this study found that female managers had higher levels of perceived business success and more profit growth than their male counterparts. For female managers, health status and business size were positively related to profit growth, while business liabilities and home-based location were negatively related to profit growth. Even though female managers had higher profit growth, they had lower levels of human and financial capital than their male manager counterparts.

\section{Savings behavior}

Family businesses depend on profit (and profit growth) and household savings to increase their net worth. The purpose of the study by Remble et al. (2014) was to examine household saving behavior and the influence on a family-owned business. This study, using the 2007 Survey on Consumer Finances and life-cycle earnings model, focused on the savings behavior of business-owning and nonbusiness-owning households. The study showed that business-owning households were more likely to save than nonbusiness-owning households. The results of this study indicate that household saving behavior was influenced by both characteristics of the respondent and the household. When considering different types of businesses, the authors found that farm and nonfarm business owning households were more likely to save than other households. When considering only businessowning households, the study revealed that farm households had significantly different and more positive saving behavior than nonfarm households. In addition, they found that having more human capital (e.g., formal education) or financial capital (e.g., possessing an Individual Retirement Account, having an employer pension, or having health insurance) increased the likelihood of household savings among familyowned businesses. 


\section{Survival duration}

Profit growth and savings are critically important for the long-term survival of family businesses. Stafford et al. (2010) examined the factors affecting long-term survival of family businesses in the United States. They used the SFBT to guide the long-term survival model and employed the National Family Business Survey and Spatial Hazard Events and Losses for the US databases. This study introduced important rigor into the survival analysis of family business by using a longitudinal sample of family businesses and controlling for community environment, family and business capital, management processes and disruptions external to the firm, such as a natural disaster. They found that family businesses that provided more income from their families, hired more temporary help, owned larger businesses, and had more experience had increased duration of survival. Home-based businesses, female owners, and those using customer-centric management strategies had decreased duration of survival.

Most importantly, they found that businesses in more economically vulnerable rural areas and businesses owners who considered their business a "way of life" had increased duration of survival. Both of these results planted seeds for future research as family businesses in economically vulnerable rural areas and those owners considering their business as a "way of life" were posited to have decreased, rather than increased duration of survival. This study provided further evidence that a family business does not make economic decisions in social isolation.

\section{Ownership and relationships}

Stafford et al. (2010) emphasized that many factors other than objective measures, such as money, are important to survival of family businesses. Subsequent research introduced other factors, such as relationships among owners (copreneurs), perceived financial solvency, and perceived resource well-being that were important for survival and success, especially for female owners and managers.

The interface between the family and business becomes increasingly important when two or more family members are active in the business. McDonald et al. (2017), using the SFBT and Intergenerational Family Business Survey, examined small and medium-sized rural copreneurial businesses and the relationship between their business structure, relationship satisfaction, and profitability. In this case, the important resource is labor because two business owners work in the family business. This research showed that couples who self-select into working together as copreneurial business owners do so based on how satisfied they are with their relationship. The findings suggest that to have higher profitability, the copreneurial couple should place importance on maintaining relationship satisfaction within the business and in the family.

\section{Ownership and satisfaction}

While copreneurs are often men and women owners, gender of the owner is an important consideration in family business because women often have dual responsibilities for the business and household. The purpose of the study by Archuleta et al. (2017), using role theory and primary data from Kansas farmers, was to explore factors that impacted farm women's perceptions of farm business financial satisfaction. The most important contributions were the following: being financially solvent, a subjective measure, was positively associated with farm business financial satisfaction, and occupying a decision-making role was negatively associated with farm business financial satisfaction. Neither household income nor percentage of agriculture income, both objective measures, were significantly associated with farm business financial satisfaction.

\section{Ownership and perceived well-being}

While an economic model would suggest that more money is better than less, Archuleta et al. (2017) found that household income or percentage of farm income were not associated with financial satisfaction. In the same vein, another family business research study using the family resource management model and primary data from daycare providers, found that research on family child care providers had similar findings, namely that household income predicts little about how providers perceived their overall resource well-being (Mimura et al. 2019). They found that perceived resource well-being was related to more subjective measures, such as past and present economic situations, demands on time, contributions providers' family members make to support the business functions, and quality and availability of community resources, rather than more objective measures, such as household income. 


\section{Business continuity and succession}

Successful family businesses often choose to pass the family business onto the next generation. For some potential heirs, especially daughters, there are many challenges. The literature published by the JFEI is largely literature reviews or data driven, rather than based on any theory or conceptual framework; however, these articles provided important insight into the succession of family businesses.

\section{Continuation commitment}

Mahto et al. (2014), using the Arthur Anderson Center for Family Business Survey (Massachusetts Mutual Insurance) survey of top executives, examined the factors that influence continuation commitment, or the family's commitment to continue the family business. They found that the top executive's age and generation (founder or successor), number of family owners, number of family meetings, and social identity were positively associated with the continuation commitment, while more education was negatively associated with the continuation commitment. In addition, the top executive's future performance expectation was positively associated with the continuation commitment.

Unless there is a continuation commitment from family it is unlikely that the business will continue in the same family. Merchant et al. (2018), examined business continuity using a sample of very small businesses in India. The aim of this study was to identify and validate factors that affected family business succession for small and medium-sized enterprises in India. The authors found that the two major drivers having the greatest positive impact on successful continuation for these Indian family businesses were willingness and excitement of the potential successor to join the business and ability of the founder and successor to manage tensions.

\section{Daughter succession}

While many family business owners are concerned about succession of the business, small business owners may be specifically concerned about their children following in their footsteps. Wang (2010) used a content analysis of previous literature to examine daughter succession in family businesses. This paper was driven by the notion that daughters are often forgotten or overlooked in family business succession. This paper presented various aspects of how gender inequality has been explained in the family business succession literature, and highlighted four areas of daughter succession in family business: exclusion of daughters, barriers to daughters' succession in family business, daughters' pathways to leadership and control, and the implications of the daughter option. The authors found that overlooking the potential of daughters as successors to a business would leave sub-optimal choices for successions, and also exclude daughters from involvement in the family business.

\section{Entrepreneurial skill succession}

Family involvement in a business may encourage the involvement of a daughter or son. Ferrando-Latorre et al. (2019) examined relationships within Spanish families to determine if children of entrepreneurs were more likely to become entrepreneurs. This study, using the Survey of Household Finances in Spain, found that children of entrepreneurial or self-employed parents were more likely to become entrepreneurs or self-employed than children of wage and salary employees. They found that transmitting entrepreneurial skills and values between generations was an important process in the transmission of entrepreneurship.

\section{Managerial and adoption strategies}

Family business survival and success depends on the ability of the family and business entities to respond to major shocks (for instance, natural disasters, change in farm programs, and other events beyond their control). Adjustment strategies included financial choices, such as choosing risky or less risky investments, employment of family or business labor, and or using time resources (labor) or financial capital (money). In this set of articles, family structure was an important determinant of the adjustment strategies chosen.

Adoption strategies of the family and the business impacted by the tobacco buyout in 2005 and 2006 were studied by Pushkarskaya and Marshall (2010) utilizing two theoretical frameworks, i.e., agricultural household model (AHM) and SFBT, and primary data from Kentucky tobacco producers. The results showed that family structure (single females, single males, older farm couples, younger farm couples, married older farmers living with younger family members, and married younger farmers with children) did have an impact on expenditure choices and adjustment strategies following a shock to the family business. For instance, younger, married farmers were more averse to 
starting a new venture compared to other household structures; couples with young children were less likely to choose the stock market for investment than an older couple living with their younger generation family; and the stock market was an investment choice for families who had experienced a family death.

\section{Adjustment strategies}

While changes in financial choices are important adoption strategies, adjusting behaviors in either the business or family system are important to accommodate the needs of the other systems when unusually heavy demands exist. The use of adjustment behaviors during high-demand times creates a resilience capacity that tends to automatically take effect when encountering a disruption. Five adjustment types occur at the family-business intersection: (1) reallocating personal time, (2) obtaining additional help, (3) adjusting family resources, (4) adjusting business resources, and (5) intertwining tasks (Fitzgerald, Winter, Miller, and Paul 2001).

\section{Women and minority adjustment strategies}

Lee et al. (2017) used the 2003 and 2005 National Minority Business Owners Surveys (NMBOS) and SFBT to compare male and female minority business owners in their overall use of adjustment strategies. They found that minority female business owners were more likely to reallocate family resources to help with business tasks and were more likely to intertwine both family and business tasks than minority male business owners when demands were particularly great for the family or the firm. Unlike in majority cultures, where male and female business owners may not differ in their use of adjustment strategies, in minority-owned small family firms, gender differences existed in adjustment strategy use. In particular, minority female business owners in this study were more likely to solicit unpaid help for their businesses and adjust family resources to meet business demands, than were minority male business owners.

\section{Capital usage}

Other adjustment strategies require changes in the use of other resources apart from time, labor, or money. Glover (2010) examined how family farm businesses use different forms of capital (economic, social, cultural, and symbolic) to respond to critical changes in the family and business using Bourdieu's theory of capital. In this study, based on case studies of farmers in the United Kingdom, Glover found that levels of economic capital were adversely affected when there is lack of contingency planning. However, both social and symbolic capital were important in assisting family members to cope and continue the family business. This study provided qualitative evidence that in adverse situations, business and family support one another to function smoothly and sustain the operation.

\section{Innovative technology adoption}

Innovative adjustment strategies include the adoption of new technologies. Niehm et al. (2010) provided new insights regarding the benefits of integrated information technology (IT) use for small family firms. This study was based on Davis et al.'s (1989) Technology Acceptance Model (TAM) and Rogers' (2003) Diffusion of Innovations framework, and utilized data from the National Family Business Survey. This study found that prior IT knowledge and the degree to which IT was used in the business had the strongest impact on technology adoption, followed by community size, access, and affordability of related technologies. The findings suggested that family firms were able to successfully implement and gain advantages from IT only after the business managers perceived its usefulness and developed technology capabilities.

\section{Values and goals}

While survival and success are important to family businesses, the underlying value orientation and goals and family business dynamics are important in enabling family businesses to survive and succeed.

\section{Value orientation}

An important study by Distelberg and Blow (2010) used the American Family Survey and a dual General Systems Theory and Eco-systems perspective to explore the congruency of goals and values and how they influence perceptions of success; how the family business's resources and goals are appraised differently based on the family business's value orientation; and how unity in values supersedes value orientation regarding the functioning of the family business. They found that value orientations were not correlated with sales, satisfaction, or perceptions of success. However, they did find that value orientations have an effect on the value 
that owners assign to goals and resources. And, they found that individuals in a family business were more satisfied with their business when personal values were consistent with the values set for the business.

\section{Goal orientation and performance}

Following the lead of Distelberg and Blow (2010), Lee and Marshall (2013) investigated the relationship between goal orientation and family business performance using the strategic management framework (Sharma et al. 1997) and the 1997 and 2000 National Family Business Surveys. More specifically, the authors were interested in determining the effect of goals on long-term success in family businesses. They found that two goals had a positive influence on longterm business performance: a positive reputation with customers and business growth.

\section{Dynamic capabilities}

Family business growth requires that the business remain competitive. Duarte Alonso et al. (2018) addressed three areas of need in family businesses, related to what family businesses do to adapt to a rapidly changing business environment, and the specific resources leveraged to remain competitive in this context. The authors studied the dynamic capabilities in the context of the family business, using the dynamic capabilities theoretical framework with primary data from Australia. Dynamic capabilities support capacities such as sensing new opportunities, seizing these opportunities by mobilizing resources, and transforming or reconfiguring business structures and assets for renewal. This study found that family businesses adapt to a changing business environment by embracing innovation to add value and efficiencies. In addition, to remain competitive, these firms leverage specific resources, such as unique firm attributes, an open culture, signature processes and idiosyncratic knowledge.

\section{Considerate exchange}

Adapting to a changing business environment assumes that family members are able to agree that changes are needed. Successful succession of a family business requires family interactions. Gezelius (2017), using social exchange theory and a sample of 580 Norwegian farmers, clarified the concept of considerate exchange and extended the capacity of social exchange theory to explain interactions among close relatives of family-owned businesses. Considerate exchange essential states "I care for you, because you care for me." This study found that considerate exchange enables family members to allocate scarce resources while sustaining and strengthening emotional ties that build well-being within the dynamics of the family and the business. In addition, this study suggests how considerate exchange may be useful to explain business dynamics and how exchange plays out, without damaging relationships.

\section{Conclusions}

The JFEI literature has added substantial breadth and depth to the family business literature; so what did we learn? Based on suggestions by Yilmazer and Schrank (2010), household and business economic research in the JFEI explored the importance of cash flow, profitability, and savings in supporting family business well-being, satisfaction, success, and survival. Business continuity and succession are important to many successful family businesses. The JFEI literature examined the importance of family member commitment, inclusion of daughters (and sons) in the succession plan, and technical skills in successfully transitioning a business to the next generation. A successful business transition often requires the family businesses to quickly adopt new strategies to rapidly changing conditions. The JFEI literature explored adjustment strategies employed by women and minority family business owners during hectic times; and, considered the importance of capital use and innovative technologies in managing the firm. Successful management strategies are supported by individual, family, and business values and goals. The JFEI literature assessed the importance of individual values and goals, dynamic capabilities of the business owner, and considerate exchange among family members in supporting a successful family business. Most importantly, the JFEI articles, utilizing theories and conceptual frameworks from several social science fields, have helped readers understand the importance of including both the family and business in any discussion of a family business.

\section{Future research}

The 20 JFEI articles have examined family businesses through several theoretical lenses, most notably economics, sociology, family science, and psychology. These 
approaches have provided a broad base for understanding family business by recognizing the importance of considering the impacts on the family and business. While an extensive body of literature has been created over the past decade, significant research opportunities remain for JFEI authors. Previous studies have profiled family businesses and examined their short- and long-term survival and success. Here are seven areas for substantive future research on family businesses:

(1) Fitzgerald et al. (2001), Yilmazer and Schrank (2010), and McDonald and Marshall (2018) provide important foundations for examining resource flows between the family and the business. Ample room exists to further study the implications of the financial interactions between households and businesses as both systems seek to adjust to these risks.

(2) Stafford et al. (2010) found that family businesses in more vulnerable communities had a longer duration of survival. Additional research is needed to investigate whether businesses in more vulnerable rural communities have higher attachment and continuation commitment than family businesses in less vulnerable urban communities.

(3) Wang (2010) demonstrates how women are often overlooked in family business succession. More research is needed on women taking over family businesses and their overall role in the succession process. With a growing trend of women-owned small firms, spousal partnerships, and women in management roles, future studies could focus on how leadership style, demographics, communication, and business characteristics affect management and ownership succession.

(4) Research has shown the benefits of considerate exchange and social exchange theory within family farms and how these interactions can cause better personal business relations (Gezelius 2017). Additional studies of considerate exchange in other settings, such as in the US and other parts of the world and to nonfarm family businesses, would provide insight into incorporating considerate exchange into social exchange theory.

(5) Following the lead of Niehm et al. (2010) more research is needed to examine the specific forms of motivational, material, and skill access related to information technology to enhance the performance of family businesses. In addition, the impact of information technology resources on economic, social, symbolic, and other capital use warrants further research.
(6) Lee et al. (2017) explored the use of adjustment strategies by minority owners. The opportunity exists to utilize the model developed by Lee et al. to examine public policy issues, such as the impact of the pandemic on family businesses and access to economic stimulus programs. In addition, further development of theory relating to capitals, ethnic identity and subjective wellbeing of family businesses owned by people of color and recent immigrants in adapting to change is warranted (Valdivia and Flores 2012).

(7) Pushkaraskaya and Marshall (2010), Archuletta et al. (2017), and Gezelius (2017) explored issues faced by agricultural producers. Given the public policy interest in classifying other businesses, such as agricultural producers, as small business enterprises, additional research is needed to explore the heterogeneity among family-owned small businesses.

In conclusion, JFEI articles have the opportunity to bring family business research from throughout the world to the academic marketplace. While family business research may employ less familiar theoretical or conceptual constructs, interesting datasets and empirical analyses provided a glimpse into the challenges faced by family businesses. The research and information on family businesses in JFEI offers a plethora of opportunities to future researchers and continues to educate the public on important family business matters. Throughout our review of JFEI family business research, much has been discovered, and the journal will continue to make substantive contributions to the literature by addressing the vexing challenges facing family businesses.

Funding No funding was provided for this literature review project.

\section{Compliance with Ethical Standards}

Conflict of interest No conflict of interest or competing interests were reported by the authors.

Informed Consent No primary data was collected using human subjects; hence, no informed consent statement was required for this literature review.

Ethical Approval Statement This paper is a literature review study. The Montana State University Institutional Review Board has confirmed that this study is exempt; hence, no ethical approval is required.

\section{Appendix}

See Tables 1 and 2 . 


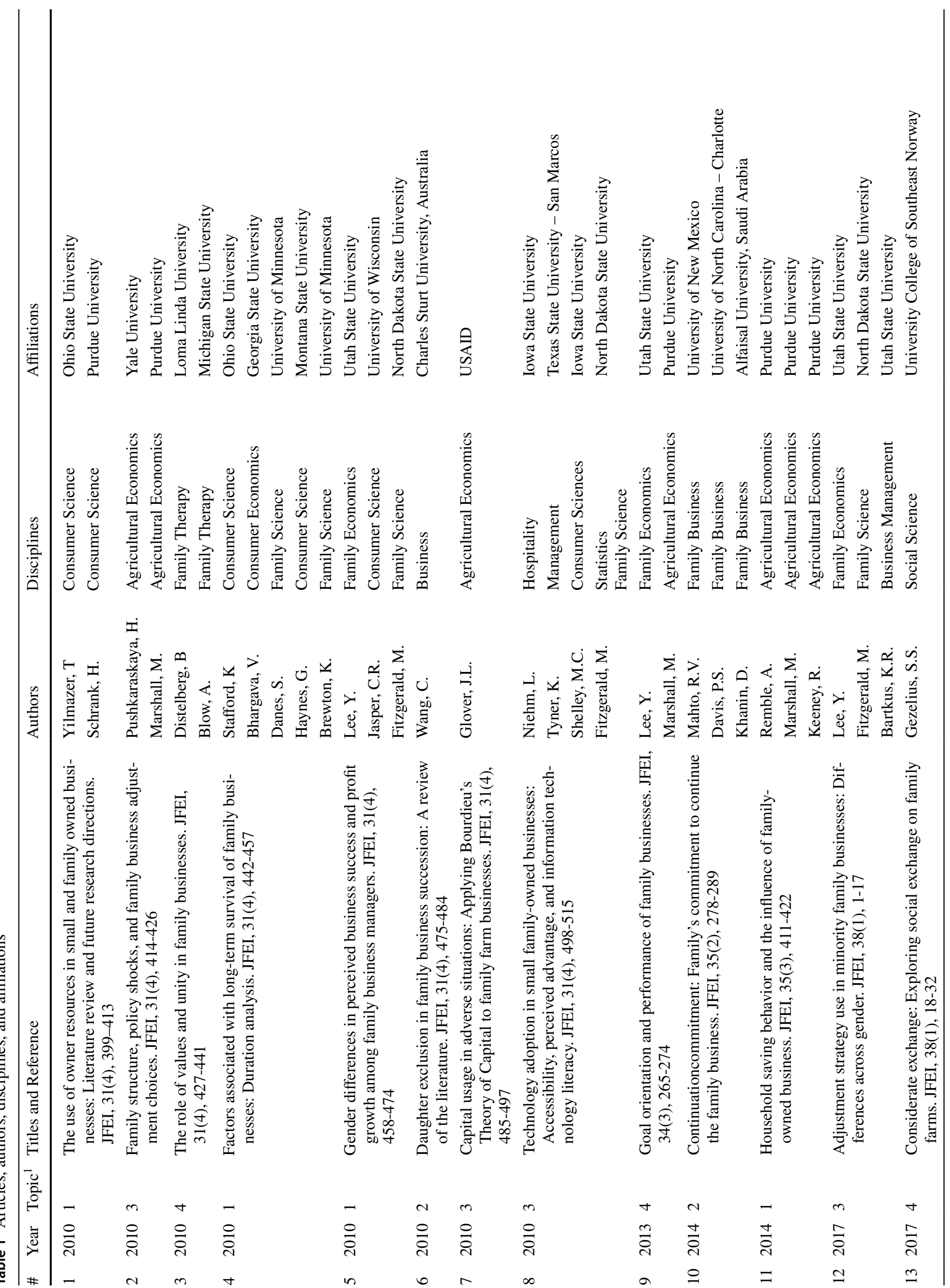




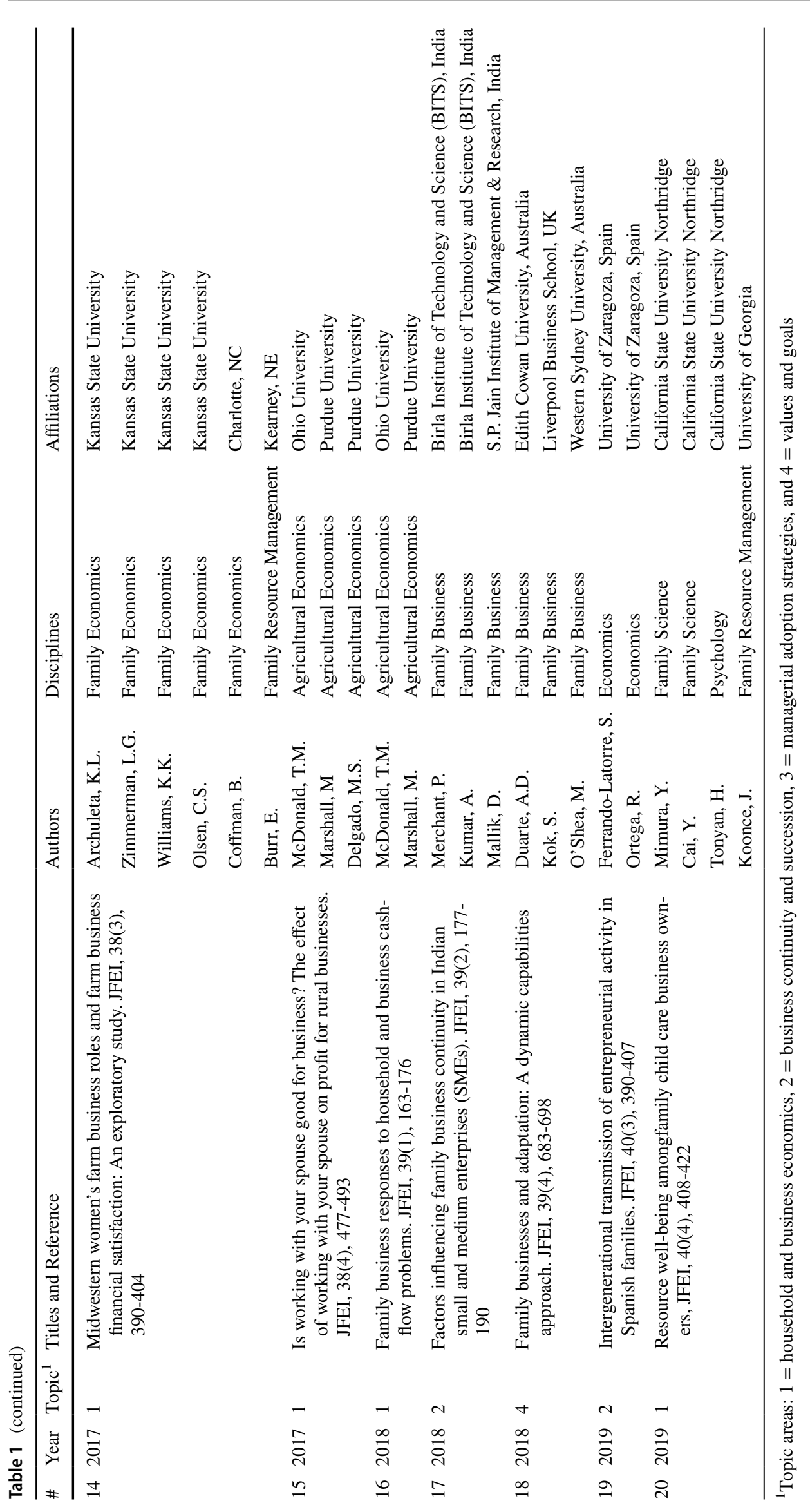




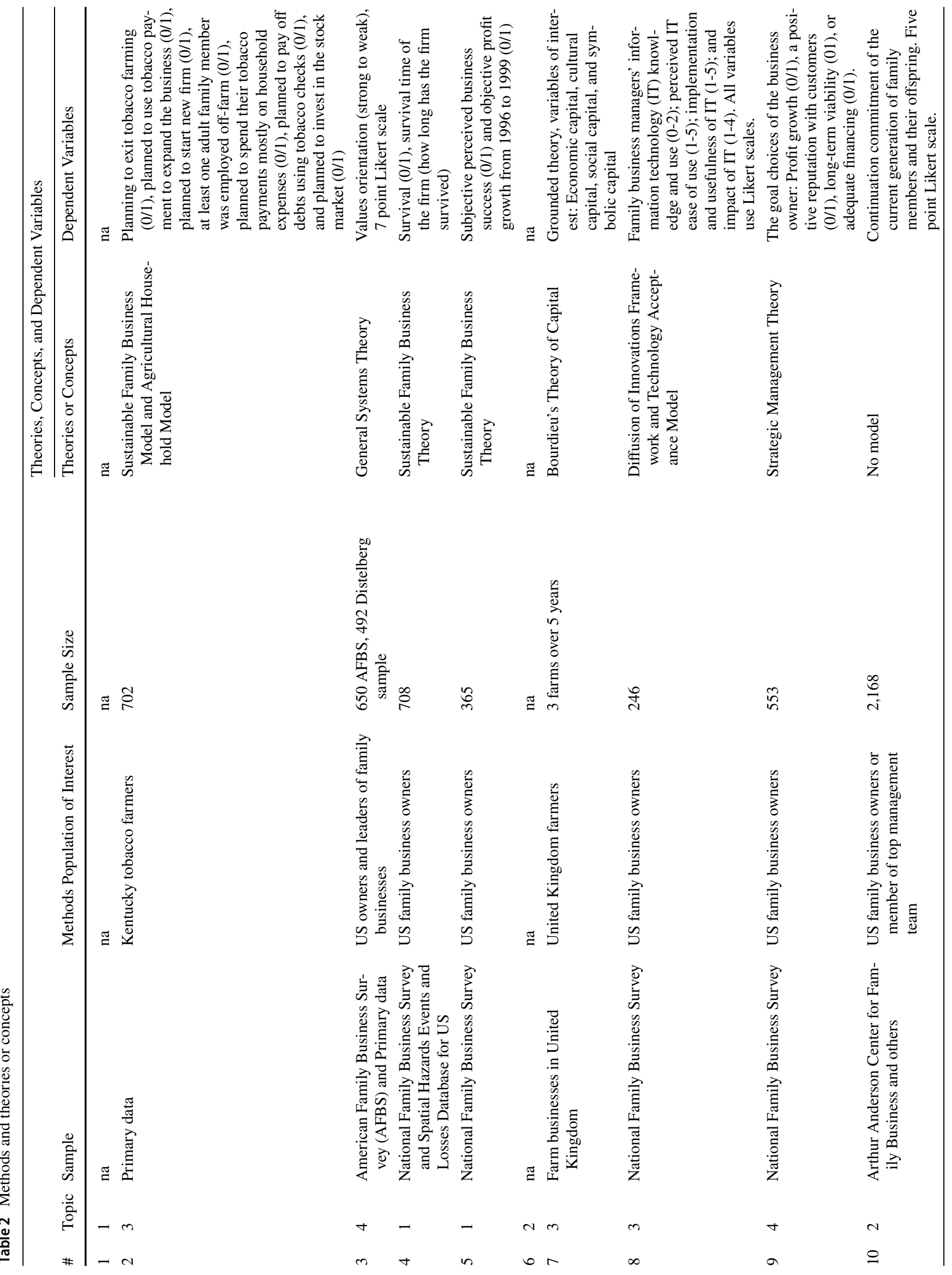




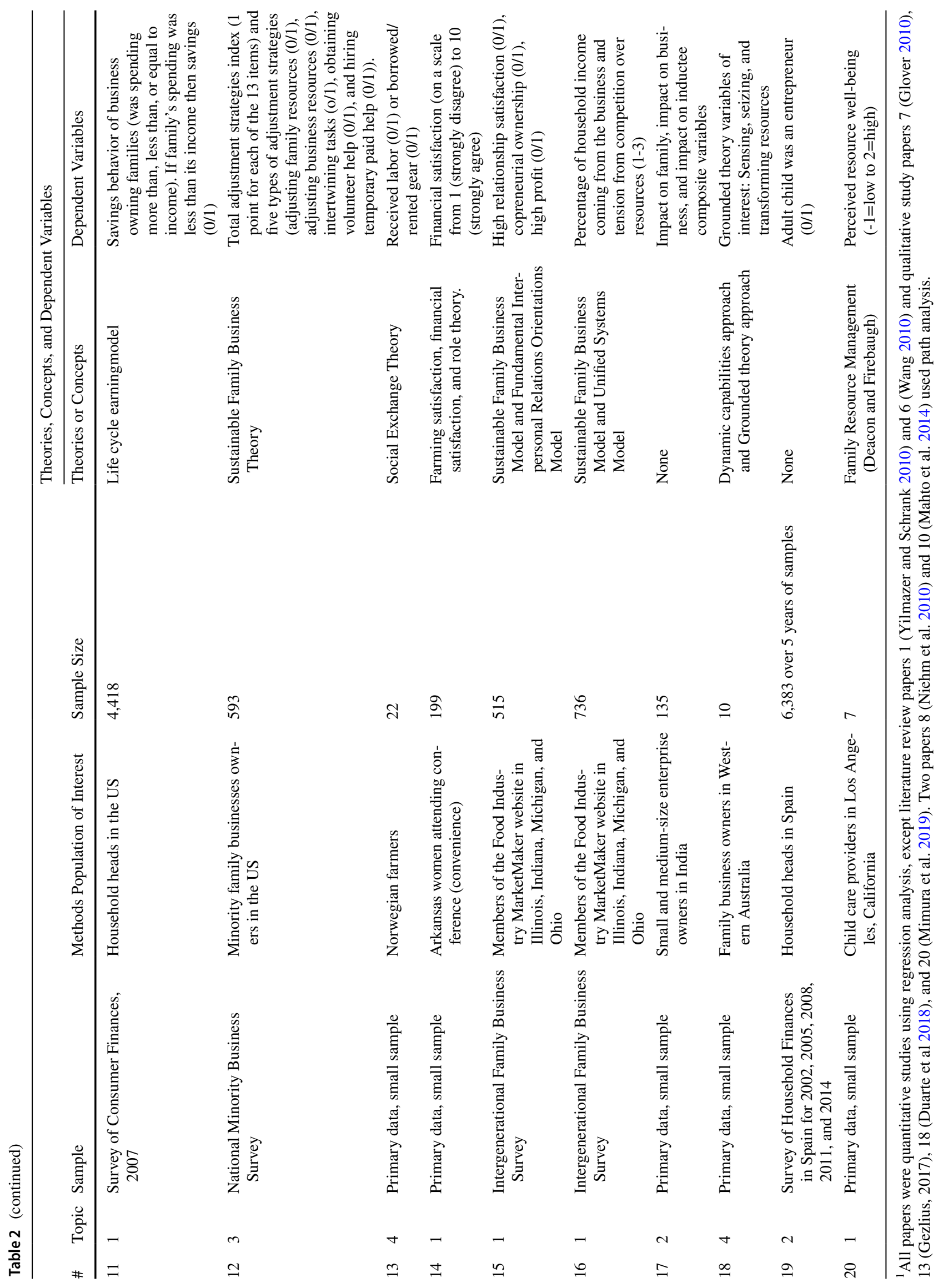




\section{References}

Archuleta, K. L., Zimmerman, L. G., Williams, K. K., Olsen, C. S., Coffman, B., \& Burr, E. (2017). Midwestern women's farm business roles and farm business financial satisfaction: An exploratory study. Journal of Family and Economic Issues, 38(3), 390-404. https://doi.org/10.1007/s10834-016-9515-2.

Biddle, B. J. (1986). Recent development in role theory. Annual Review of Sociology, 12, 67-92. https://doi.org/10.1146/annur ev.so.12.080186.000435.

Coughenour, C. M., \& Swanson, L. E. (1992). Determinants of farmers' satisfactions with farming and with life: A replication and extension. Southern Rural Sociology, 9(1), 45-70 Retrieved from http://www.ag.auburn.edu/auxiliary/srsa/pages/Articles/SRS\%20 1992\%209/SRS\%201992\%209\%201\%2045-70.pdf.

Davis, F. D., Bagozzi, R. P., \& Warshaw, P. R. (1989). User acceptance of computer technology: A comparison of two theoretical models. Management Science, 35(8), 982-1002. https://doi.org/10.1287/ mnsc.35.8.982.

Deacon, R. E., \& Firebaugh, F. M. (1988). Family resource management: Principles and applications (2nd ed.). Needham Heights: Allyn and Bacon, Inc.

Distelberg, B., \& Blow, A. (2010). The role of values and unity in family businesses. Journal of Family and Economic Issues, 31(4), 427-441. https://doi.org/10.1007/s10834-010-9221-4.

Duarte Alonso, A., Kok, S., \& O'Shea, M. (2018). Family businesses and adaptation: A dynamic capabilities approach. Journal of Family and Economic Issues, 39(4), 683-698. https://doi.org/10.1007/ s10834-018-9586-3.

Emerson, R. M. (1981). Social Exchange Theory. In M. Rosenberg \& R. H. Turner (Eds.), Social psychology: Sociological perspectives (pp. 30-65). New York: Basic Books.

Ferrando-Latorre, S., Velilla, J., \& Ortega, R. (2019). Intergenerational transmission of entrepreneurial activity in Spanish families. Journal of Family and Economic Issues, 40(3), 390-407. https://doi. org/10.1007/s10834-019-09613-7.

Fitzgerald, M. A., Winter, M., Miller, N. J., \& Paul, J. J. (2001). Adjustment strategies in the family business: Implications of gender and management role. Journal of Family and Economic Issues, 22, 265-291. https://doi.org/10.1023/A:1016651906925.

Gezelius, S. S. (2017). Considerate exchange: Exploring social exchange on family farms. Journal of Family and Economic Issues, 38(1), 18-32. https://doi.org/10.1007/s10834-016-9496-1.

Glover, J. L. (2010). Capital usage in adverse situations: Applying Bourdieu's Theory of Capital to family farm businesses. Journal of Family and Economic Issues, 31(4), 485-497. https://doi. org/10.1007/s 10834-010-9225-0.

Habbershon, T. G., Williams, M., \& MacMillan, I. C. (2003). A unified systems perspective of family firm performance. Journal of Business Venturing, 18(4), 451-465. https://doi.org/10.1016/s0883 -9026(03)00053-3.

Joo, S. H., \& Grable, J. E. (2004). An exploratory framework of the determinants of financial satisfaction. Journal of Family and Economic Issues, 25(1), 25-50. https://doi.org/10.1023/b:jeei.00000 16722.37994.9f.

Lee, Y. G., \& Marshall, M. I. (2013). Goal orientation and performance of family businesses. Journal of Family and Economic Issues, 34(3), 265-274. https://doi.org/10.1007/s10834-012-9329-9.

Lee, Y. G., Jasper, C. R., \& Fitzgerald, M. A. (2010). Gender differences in perceived business success and profit growth among family business managers. Journal of Family and Economic Issues, 31(4), 458-474. https://doi.org/10.1007/s10834-010-9226-z.

Lee, Y. G., Fitzgerald, M. A., \& Bartkus, K. R. (2017). Adjustment strategy use in minority family businesses: Differences across gender. Journal of Family and Economic Issues, 38(1), 1-17. https ://doi.org/10.1007/s10834-015-9478-8.

Mahto, R. V., Davis, P. S., \& Khanin, D. (2014). Continuation commitment: Family's commitment to continue the family business. Journal of Family and Economic Issues, 35(2), 278-289. https:// doi.org/10.1007/s10834-013-9367-y.

McDonald, T. M., \& Marshall, M. I. (2018). Family business responses to household and business cash-flow problems. Journal of Family and Economic Issues, 39(1), 163-176. https://doi.org/10.1007/ s10834-017-9543-6.

McDonald, T. M., Marshall, M. I., \& Delgado, M. S. (2017). Is working with your spouse good for business? The effect of working with your spouse on profit for rural businesses. Journal of Family and Economic Issues, 38(4), 477-493. https://doi.org/10.1007/s1083 4-017-9525-8.

Merchant, P., Kumar, A., \& Mallik, D. (2018). Factors influencing family business continuity in Indian small and medium enterprises (SMEs). Journal of Family and Economic Issues, 39(2), 177-190. https://doi.org/10.1007/s10834-017-9562-3.

Mimura, Y., Cai, Y., Tonyan, H., \& Koonce, J. (2019). Resource wellbeing among family child care business owners. Journal of Family and Economic Issues, 40(3), 408-422. https://doi.org/10.1007/ s10834-019-09620-8.

Niehm, L. S., Tyner, K., Shelley, M. C., \& Fitzgerald, M. A. (2010). Technology adoption in small family-owned businesses: Accessibility, perceived advantage, and information technology literacy. Journal of Family and Economic Issues, 31(4), 498-515. https:// doi.org/10.1007/s10834-010-9197-0.

Pushkarskaya, H., \& Marshall, M. I. (2010). Family structure, policy shocks, and family business adjustment choices. Journal of Family and Economic Issues, 31(4), 414-426. https://doi.org/10.1007/ s10834-010-9231-2.

Remble, A. A., Marshall, M. I., \& Keeney, R. (2014). Household saving behavior and the influence of family-owned business. Journal of Family and Economic Issues, 35(3), 411-422. https://doi. org/10.1007/s10834-013-9372-1.

Rogers, E. M. (2003). Diffusion of innovations (5th ed.). New York, NY: Free Press.

Schutz, W. C. (1958). FIRO: A three dimensional theory of interpersonal behavior. New York: Rinehart.

Sharma, P., Chrisman, J. J., \& Chua, J. H. (1997). Strategic management of the family business: Past research and future challenges. Family Business Review, 10(1), 1-16. https://doi.org/10.111 1/j.1741-6248.1997.00001.x.

Singh, I., Squire, L., \& Strauss, J. (1986). A survey of agricultural household models: Recent findings and policy implications. The World Bank Economic Review, 1(1), 149-179. https://doi. org/10.1093/wber/1.1.149.

Stafford, K., Duncan, K. A., Dane, S., \& Winter, M. (1999). A research model of sustainable family businesses. Family Business Review, 12(3), 197-208. https://doi.org/10.1111/j.1741-6248.1999.00197 $\mathrm{x}$.

Stafford, K., Bhargava, V., Danes, S. M., Haynes, G., \& Brewton, K. E. (2010). Factors associated with long-term survival of family businesses: Duration analysis. Journal of Family and Economic Issues, 31(4), 442-457. https://doi.org/10.1007/s10834-010-9232-1.

Teece, D. J., Pisano, G., \& Shuen, A. (1997). Dynamic capabilities and strategic management. Strategic Management Journal, 18(7), 509-533. https://doi.org/10.1002/(sici)1097-0266(19970 8)18:7\%3C509::aid-smj882\%3E3.0.co;2-z.

Valdivia, C., \& Flores, L. Y. (2012). Factors Affecting the Job Satisfaction of Latino/a Immigrants in the Midwest. Journal of Career Development, 39(1), 31-49. https://doi.org/10.1177/0894845310 386478. 
von Bertalanffy, L. (1976). General systems theory: Foundations, development, applications. New York: George Braziller.

Wang, C. (2010). Daughter exclusion in family business succession: A review of the literature. Journal of Family and Economic Issues, 31(4), 475-484. https://doi.org/10.1007/s10834-010-9230-3.
Yilmazer, T., \& Schrank, H. (2010). The use of owner resources in small and family owned businesses: Literature review and future research directions. Journal of Family and Economic Issues, 31(4), 399-413. https://doi.org/10.1007/s10834-010-9224-1. 